\title{
Structure/property (constitutive and dynamic strength/damage) characterization of additively manufactured 316L SS
}

\author{
G.T. Gray $\mathrm{III}^{1}$, V. Livescu ${ }^{1}$, P.A. Rigg ${ }^{2}$, C.P. Trujillo ${ }^{1}$, C.M. Cady ${ }^{1}$, S.R. Chen ${ }^{1}$, J.S. Carpenter ${ }^{1}$, \\ T.J. Lienert ${ }^{1}$, and S. Fensin ${ }^{1}$ \\ ${ }^{1}$ Los Alamos National Laboratory, Los Alamos, New Mexico 87545, USA \\ ${ }^{2}$ Institute for Shock Physics, Washington State University, Pullman, Washington 99164, USA
}

\begin{abstract}
For additive manufacturing (AM), the certification and qualification paradigm needs to evolve as there exists no "ASTM-type" additive manufacturing certified process or AM-material produced specifications. Accordingly, utilization of AM materials to meet engineering applications requires quantification of the constitutive properties of these evolving materials in comparison to conventionally-manufactured metals and alloys. Cylinders of 316L SS were produced using a LENS MR-7 laser additive manufacturing system from Optomec (Albuquerque, NM) equipped with a $1 \mathrm{~kW}$ Yb-fiber laser. The microstructure of the AM-316L SS is detailed in both the as-built condition and following heat-treatments designed to obtain full recrystallization. The constitutive behavior as a function of strain rate and temperature is presented and compared to that of nominal annealed wrought 316L SS plate. The dynamic damage evolution and failure response of all three materials was probed using flyer-plate impact driven spallation experiments at a peak stress of $4.5 \mathrm{GPa}$ to examine incipient spallation response. The spall strength of AM-produced 316L SS was found to be very similar for the peak shock stress studied to that of annealed wrought or AM-316L SS following recrystallization. The damage evolution as a function of microstructure was characterized using optical metallography.
\end{abstract}

\section{Introduction}

Additive manufacturing (AM) technology is a key enabling technology fueling the revolutionary transformations occurring in rapid prototyping, freeform and net-shape manufacturing, and local production at a global scale. AM offers increased efficiencies in energy, cost, and material savings in manufacturing [1-5]. However, for AM materials or components to supplant conventional manufactured materials and processes, the certification and qualification paradigm needs to evolve as there exists no "ASTM-type" additive manufacturing certified process or AM-material produced specifications. Even for small changes in starting feed material (powder or wire), component geometry, build process variables, and post-build thermo-mechanical processing, the qualification cycle can be complicated leading to long implementation times for even minor changes. This is due in large part to the fact that we are not able to predict and control processingstructure-property-performance (PSPP) relationships [68]. Metallic-component certification requirements have been documented elsewhere in the case of some manufacturing processes but generally involve meeting engineering and physics requirements tied to the functional requirements of the engineering component and finally process and product qualification. For AM materials and components to meet qualification and certification requirements for critical engineering applications, key microstructural parameters and defects must be quantified and quantitatively linked to processing and equipment parameters to establish minimum performance properties [9].
316 stainless steel is a ubiquitous austenitic SS that is often used in marine and medical environments because of its combination of strength and corrosion resistance. The pervasiveness of use and wide availability of inexpensive feedstock for additive manufacturing, has lead to several recent publications that focus on this particular alloy system [10-13]. In several of these studies connections are made between defects, such as porosity, and performance in standard mechanical behavior tests $[10,12]$. Although this property data is important in qualifying AM products, a major concern when comparing AM parts with those made in traditional methods is the failure and damage mechanisms that arise from the unique microstructures. Some studies exist in the area of high cycle fatigue that begin to make these connections. [14,15] but none for the 316 stainless steel series. Further, no studies of the dynamic damage evolution due to shock spallation loading of an AM-produced 316L SS material has been conducted to date. The purpose of this study is to report initial constitutive and dynamic fracture (spallation) properties of 316L SS produced by Laser Engineered Net Shaping (LENS) additive manufacturing in comparison to wrought 316L SS as a result of their microstructures.

\section{Experimental procedure}

\subsection{Material - processing}

This study involved production, characterization and testing of solid cylinders of $316 \mathrm{~L}$ austenitic stainless steel(hereafter $316 \mathrm{~L}$ SS) produced by laser additive manufacturing and contrasted to wrought 316L SS plate. 
Table 1. Chemical Analysis of Wrought 316L SS plate and 316L SS Powder.

\begin{tabular}{|l|c|c|c|c|c|}
\hline Wt.\% & $\mathbf{C}$ & $\mathbf{C r}$ & $\mathbf{C u}$ & $\mathbf{M n}$ & Mo \\
\hline Wrought & 0.022 & 16.16 & 0.39 & 1.70 & 2.08 \\
\hline Powder & 0.02 & 20.7 & 0.19 & 1.32 & 2.45 \\
\hline Wt.\% & $\mathbf{N}$ & $\mathbf{N i}$ & $\mathbf{P}$ & $\mathbf{S}$ & $\mathbf{S i}$ \\
\hline Wrought & 0.063 & 10.03 & 0.029 & 0.0004 & 0.40 \\
\hline Powder & 0.09 & 11.4 & 0.02 & 0.01 & 0.50 \\
\hline
\end{tabular}

The wrought $316 \mathrm{~L} \mathrm{SS}$ was procured in $12.5 \mathrm{~mm}$-thick plate form. The analyzed chemical composition of the wrought plate 316L SS (wt. pct.) is shown in Table 1. The crystallographic texture of the 316L SS investigated was investigated using X-ray diffraction to be almost random in nature. The 316L powder was procured from Carpenter Powder Products (Bridgewater, PA) and was produced using atomization techniques. The analyzed chemical composition of the $316 \mathrm{~L}$ SS powder (wt. pct.) is also provided in Table 1. An inert gas fusion method (ASTM E 1019-11) was used to determine the wt.\% oxygen for the powder $(0.013 \%)$ and the deposit $(0.018 \%)$. The powder particle size distribution was $-80 /+270$ mesh (53 um to $180 \mathrm{um}$ ) and was determined using standard sieve analysis of metal powders.

Cylinders of 316L SS were produced using a LENS MR-7 laser AM system from Optomec (Albuquerque, $\mathrm{NM}$ ) equipped with a $1 \mathrm{~kW}$ Yb-fiber laser. The laser beam was delivered to the collimator with a $200 \mathrm{um}$ stepped index fiber optic and was focused via a lens to a focus length of $160.4 \mathrm{~mm}$. The laser focus condition was arranged so that the minimum waist of the focused beam was positioned $\sim 3.8 \mathrm{~mm}$ below the substrate surface. The laser power employed throughout the trials was $380 \mathrm{~W}$.

The laser beam was directed normal to the substrate and passed through a nozzle $\sim 20 \mathrm{~mm}$ in diameter accompanied by anargon shield gas with a flow rate of $20 \mathrm{lpm}$ to prevent damage to the optics. Powder was delivered to the deposition region through four nozzles with exit orifices positioned concentrically around the larger nozzle. The exit orifices of the nozzles were positioned approximately $9.5 \mathrm{~mm}$ above the substrate surface. The four nozzles were arranged symmetrically about the laser beam axis and were angled downward toward the substrate at $\sim 45$ degrees. A mass flow rate of the powder of $\sim 6.3 \mathrm{gm} \cdot \mathrm{min}^{-1}$ was determined by averaging three measurements conducted by capturing powder for one minute from the nozzles in a plastic bag.

The AM components produced were solid cylinders $2.5 \mathrm{~cm}$ in diameter and $3.3 \mathrm{~cm}$ tall. The cylinder was deposited onto a substrate comprised of a $0.95 \mathrm{~cm}$ thick plate of $304 \mathrm{~L}$ SS. A z step height of $0.3 \mathrm{~mm}$ was used with a hatch spacing of $0.46 \mathrm{~mm}$. Each layer was produced using linear "hatching" passes at $1.12 \mathrm{~cm} \mathrm{~s}^{-1}$. The direction of the hatching passes was alternated between $0^{\circ}$ and $90^{\circ}$ directions for every other layer. Oxygen levels were monitored throughout building and did not exceed $6 \mathrm{ppm}$ at any point. The powder feed rate was set at 3.5 RPM and was held constant during the build. After AM fabrication, the 304L substrates were machined away. One cylinder was sectioned to provide
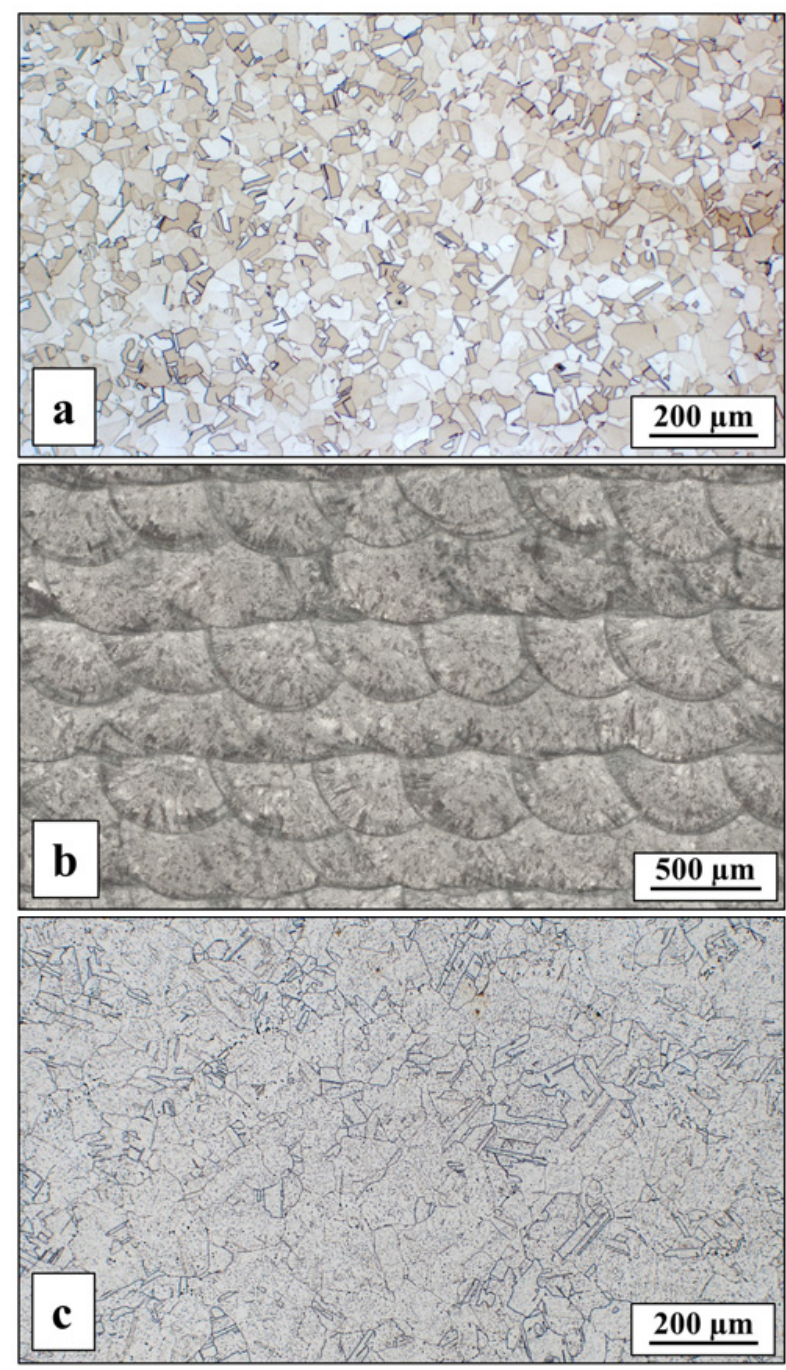

Figure 1. Optical microscopy of the $316 \mathrm{~L}$ SS materials studied: a) annealed wrought plate, b) AM-(As-Built), and c) AM-following recrystallization heat-treatment at $1060 \mathrm{C}$ for 1 hour (AM-Rx).

AM-as-built samples while the other was heat-treated. The heat treatment was $1060{ }^{\circ} \mathrm{C}$ for one hour under vacuum followed by cooling to room temperature in $2 \frac{1}{2}$ minutes by rapid Argon gas quenching. The heat treatment leads to an AM-recrystallized microstructure (hereafter referred to as AM-Rx).

Samples from the three starting 316L SS materials were sectioned and prepared following standard metallographic procedures including polishing to a mirror finish and etching. Optical microscopy images were acquired at various magnifications using a Zeiss Axio Imager M2m optical microscope. The microstructures of the three $316 \mathrm{~L}$ SS materials investigated are shown in Fig. 1. The annealed wrought plate material is seen to exhibit a fine-grained equiaxed microstructure. The AM-As-Built displays a macroscopic squamous or fish-scale type morphology indicative of the deposit interfaces of the alternate layers of the build. Each "fish scale" exhibits a fine-grained microstructure with elongated grains along the periphery and equiaxed grains in the center. The as-deposited 


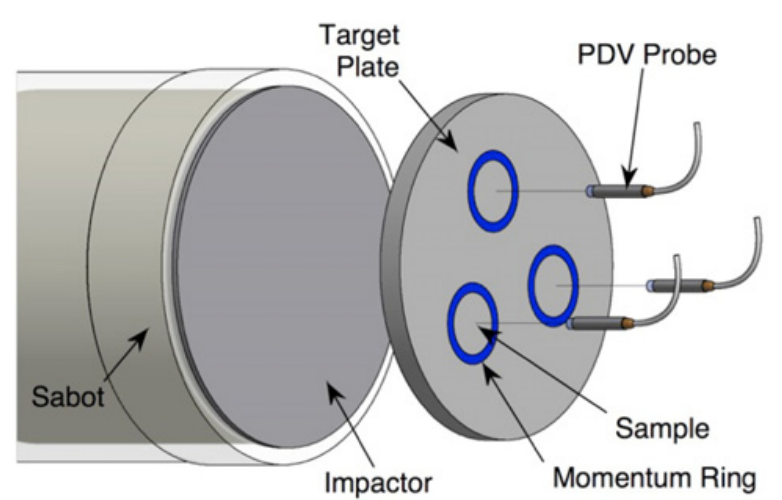

Figure 2. Experimental configuration used to produce incipient damage or complete spall in three samples simultaneously. Wrought $316 \mathrm{~L}$ SS impactors were accelerated in a $80 \mathrm{~mm}$ gas gun and impacted onto the target. PDV probes were placed over the center of each sample to provide free-surface velocimetry data from each sample in each experiment.

microstructure was characterized by a network of lacy ferrite (BCC) phase in a matrix of austenite (FCC) due to the primary solidification to ferrite [16]. The AM-Rx displayed a nominally polycrystalline microstructure albeit coarser and not as faceted as the equiaxed microstructure of the wrought $316 \mathrm{~L} \mathrm{SS}$.

\subsection{Constitutive/spallation characterization}

Cylindrical samples, with the compression axis parallel to the AM cylinder axis and thru-thickness to the wrought plate, were electro-discharge machined to dimensions of $5 \mathrm{~mm}$ in height and $5 \mathrm{~mm}$ in diameter. Quasi-static compression tests were conducted using an Instron screwdriven test system at a strain rate of $0.001 \mathrm{~s}^{-1}$ and temperature of $298 \mathrm{~K}$, with $\mathrm{MoSi}_{2}$ lubrication to minimize barreling. Strain-rate jump tests from 0.001 to $0.1 \mathrm{~s}^{-1}$ were conducted at $233 \mathrm{~K}$ to assess the strain-rate sensitivity of the three materials.

Spallation experiments were performed using the configuration shown in Fig. 2. Impactors of wrought $316 \mathrm{~L}$ SS were accelerated using an $80 \mathrm{~mm}$ bore gas gun at a velocity of nominally $250 \mathrm{~m} / \mathrm{s}$ and impacted onto the $316 \mathrm{~L}$ SS targets. All impactors were roughly $2.5 \mathrm{~mm}$ thick. Each target consisted of three separate components: a target plate, one, two, or three samples, and a momentum ring for each sample. Targets were $5 \mathrm{~mm}$ thick and designed specifically such that recovery of the shocked samples was facilitated for post-mortem examination. The samples were press-fit into the momentum rings and the rings pressfit into the target plate to ensure intimate contact of all components initially. Single sample spallation experiments were done as described elsewhere [17]. For the twoand three-sample targets, samples were machined as right circular cylinders $12.7 \mathrm{~mm}$ in diameter from wrought, as-built additively manufactured, and the AM-Rx 316L material. In the experiment, the impactor thickness was one-half the sample thickness to cause tensile damage to occur in the center of the samples. Samples were surrounded by momentum trapping rings made from wrought material with an inner diameter (ID) $0.1 \mathrm{~mm}$ less

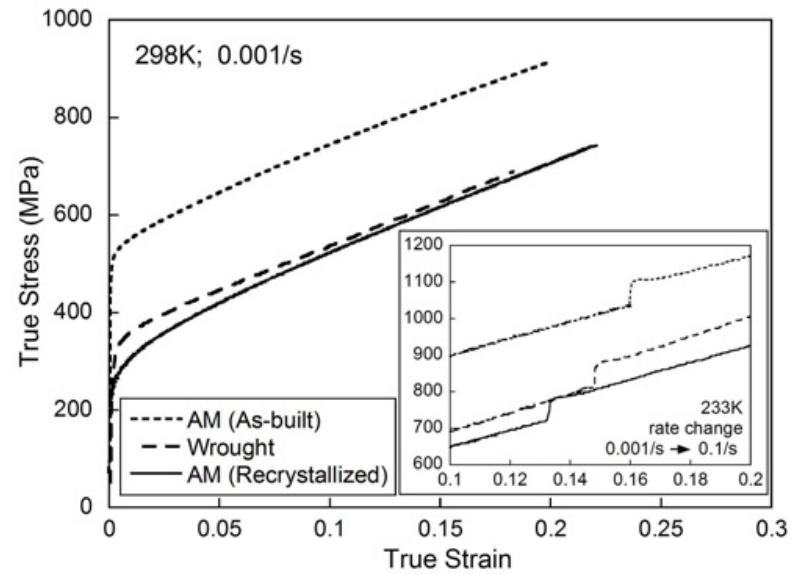

Figure 3. Compressive True Stress-True Strain of 316L SS in the AM-as-built condition, AM + recrystallization heat-treatment, and annealed wrought 316L SS.

than the outer diameter (OD) of the sample. The OD of the rings was $16.5 \mathrm{~mm}$ with the holes in the target plate made to $16.4 \mathrm{~mm}$ diameter to accommodate press fitting of all parts. The assembled targets were lapped flat and parallel to within 5 micrometers.

Samples were placed in the target ring such that the shortest distance between sample edges to each other and to the edge of the target plate were equal. Free surface velocities were measured in each experiment using Photon Doppler Velocimetry (PDV) [18,19]. Collimated probes provided by AC Photonics (Part \#: 1CL15P020LC-C01) were positioned to collect velocimetry data from the center of each sample and connected to a LANL-built 4-channel PDV system. One additional PDV probe (not shown in figure) was placed next to each target plate to measure the projectile velocity directly to an accuracy of $0.1 \%$ [19]. A single PZT trigger pin (Dynasen, Inc.) was also positioned next to each target plate with a typical standoff distance of a few millimeters to provide a trigger to the digitizer used to collect the PDV data.

\section{Results and discussion}

\subsection{Constitutive response}

The quasi-static compressive constitutive response of the three 316L SS materials is shown in Fig. 3. The as-built AM material exhibits twice the yield strength of the AM$\mathrm{Rx}$ material and $\sim 60 \%$ higher yield than the annealed wrought plate. Following yielding, all three materials display similar rates of work hardening (work-hardening slopes). To evaluate if the higher flow stress levels in the AM-as-built material was indicative of a higher starting dislocation density or level of residual stress, strain rate jump tests were conducted at 233 and $298 \mathrm{~K}$.

The magnitude of flow stress increase with the strain rate jumps was seen to be invariant for all three materials; see the rate-jump insert in Fig. 3 conducted at $233 \mathrm{~K}$. The similarity in rate jump response suggests the higher starting yield and flow stress displayed by the AM-asbuilt material is due to an intrinsic barrier component to the strength [20] consistent with the extremely fine 


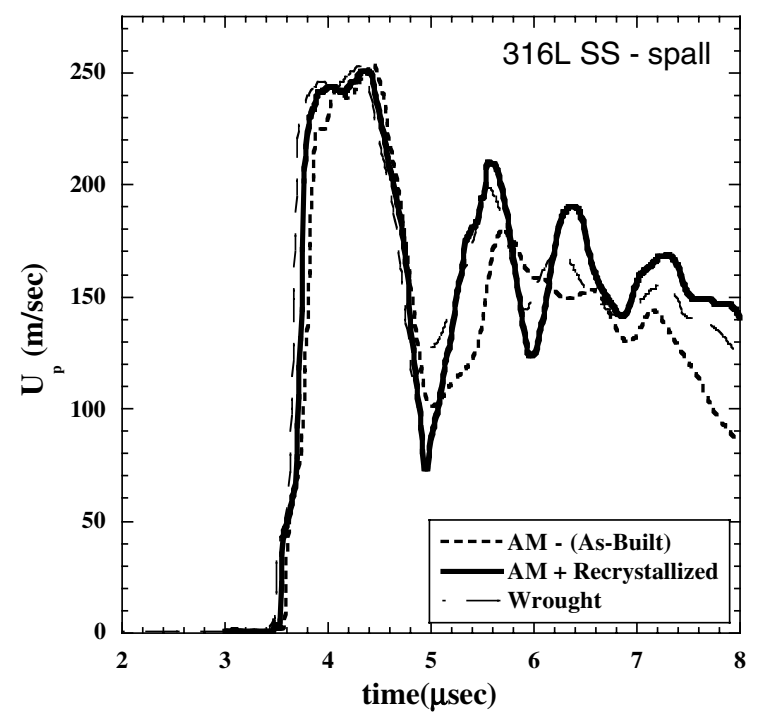

Figure 4. PDV wave profiles (particle velocity versus time plot) for the three $316 \mathrm{~L} \mathrm{SS}$ materials impacted at $257 \mathrm{~m} / \mathrm{sec}$.

dendritic substructure, within the coarser "fish-scale" macrostructure, formed during the additive manufacturing solidification and not related to either a high starting defect population or residual stresses.

\subsection{Velocimetry}

The PDV data for the three 316L SS materials spallation experiments conducted at a peak impact velocity of $257 \mathrm{~m} / \mathrm{s}$ is presented in Fig. 4. The wave profiles for the three materials are seen to display: 1) nominally similar elastic-plastic transitions, or Hugoniot Elastic Limits (HEL's), as seen in the loading portion of the profile, 2) non-constant responses upon the peak stress on the Hugoniot suggestive of non-uniform plastic deformation with the samples, most evident in the AM-as-built material, 3) slightly different magnitudes(depth) of "pull-back" signals suggesting different damage nucleation and growth responses with the wrought and AM-as-built displaying bi-linear pull-back slopes perhaps indicative of differing energy partitioning during nucleation and growth of damage as compared to the $\mathrm{AM}+\mathrm{Rx}$ displaying a linear "pull-back" signal, and 4) the AM-as-built displaying a shifted time interval of the "pull-back" signal reload peak consistent with the evolved damage in the sample not located solely near the center line of the sample, thereby altering the "ringing" interval in the pull-back signal, in contrast to the wrought and $\mathrm{AM}+\mathrm{Rx}$ samples where the incipient damage is centered near the mid-plane of the sample thickness. The difference in the magnitude of the "pull-back" signals for the three materials and the calculated spall strengths is presented for the three 316L SS samples in Table 2.

The spall strength $\left(\sigma_{\text {spall }}\right)$ was calculated using the relationship for a material that exhibits an elasto-plastic behavior [21]:

$$
\sigma_{\text {spall }} \equiv \rho_{0} C_{L} \Delta F S V\left(1+\frac{C_{L}}{C_{o}}\right)^{-1}
$$

Table 2. 316L SS Spall Data.

\begin{tabular}{|c|c|c|c|c|c|}
\hline $\begin{array}{c}\text { 316L SS } \\
\text { Material }\end{array}$ & $\begin{array}{c}\mathbf{C}_{0} \\
(\mathbf{m} / \mathbf{s e c})\end{array}$ & $\begin{array}{c}\mathbf{C}_{\mathbf{L}} \\
(\mathbf{m} / \mathbf{s e c})\end{array}$ & $\begin{array}{c}\text { Peak Stress } \\
(\mathbf{G P a})\end{array}$ & $\begin{array}{c}\Delta \mathbf{F S V} \\
(\mathbf{m} / \mathbf{s e c})\end{array}$ & $\begin{array}{c}\text { Spall } \\
(\mathbf{G P a}) \\
(\mathbf{G P a})\end{array}$ \\
\hline AM & 4474 & 5734 & 4.54 & 143.3 & 2.87 \\
\hline AM-Rx & 4464 & 5722 & 4.54 & 172.1 & 3.43 \\
\hline Wrought & 4358 & 5701 & 4.44 & 131.0 & 2.57 \\
\hline
\end{tabular}
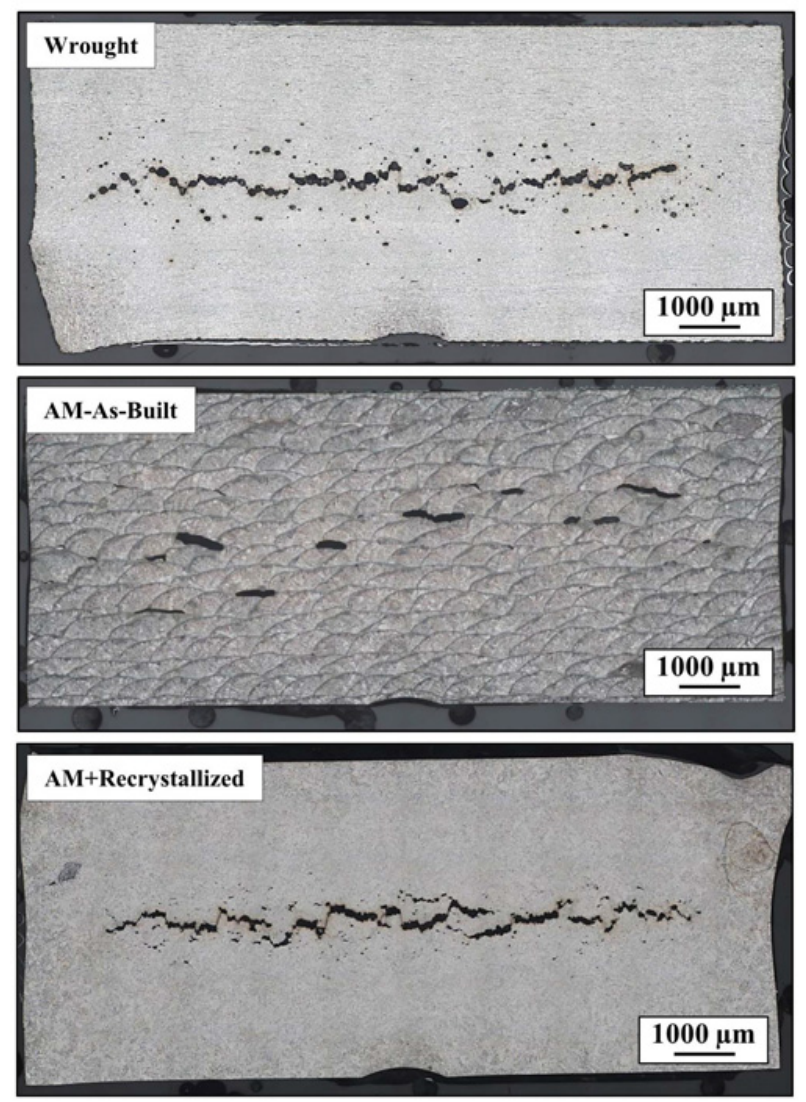

Figure 5. Macroscopic optical metallography of incipiently spalled 316L SS in the AM-as-built condition, AM + Rx, and annealed wrought $316 \mathrm{~L} \mathrm{SS}$.

where $C_{L}=5730(A M), 5720(A M-R x)$ and 5700 (wrought) $\mathrm{m} / \mathrm{s}$ is the longitudinal sound speed and $\triangle \mathrm{FSV}$ is the difference in the free surface velocity from the peak state to the minima.

\subsection{Post-mortem metallurgical analysis}

The three samples from the spallation experiment were cross-sectioned along the diameter, then prepared and inspected as described in Sect. 2.1. The damage evolution in the incipiently spalled $316 \mathrm{~L} \mathrm{SS}$ materials was seen to vary between the three materials more significantly than suggested by the three spall strengths. Figure 5 presents the macroscopic optical metallographic cross-sections, following polishing and etching, of the incipiently spalled three 316L SS spall samples. On a coarse scale the first apparent difference is in the position of the incipient damage. In the wrought and AM+Rx samples the damage field is centered in the thickness direction. This is consistent with the selection of the impactor thickness 

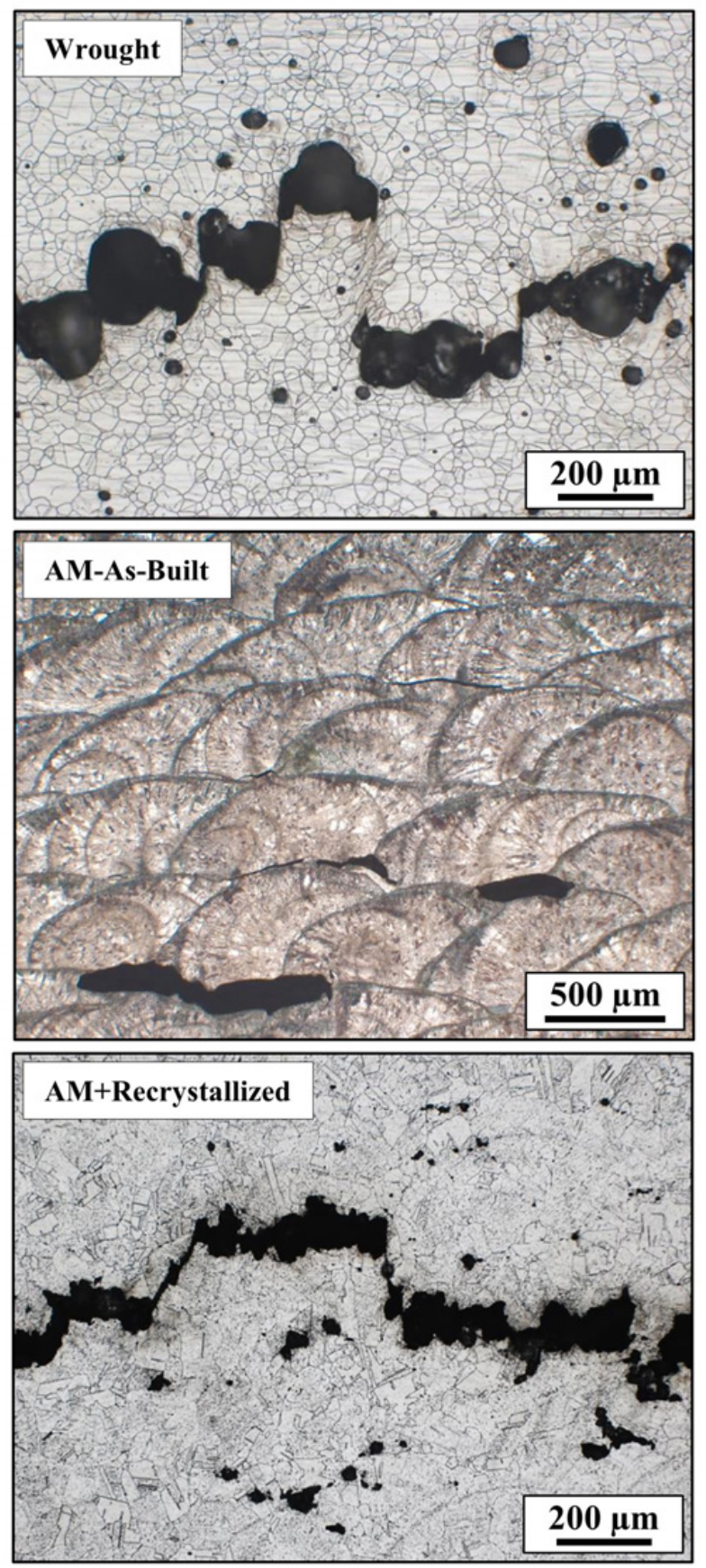

Figure 6. Higher magnification optical micrographs of damage evolution in incipiently spalled $316 \mathrm{~L}$ SS in the AM-as-built condition, AM+Rx, and annealed wrought 316L SS.

being one-half the sample thickness and thereby placing the maximum tensile stress field in the middle of the sample. Conversely, the AM-as-built displays incipient crack formation following layer solidification boundaries located along the sample mid-plane as well as further from the center of the sample thickness.

The macroscopic damage evolution of the three 316L SS samples is observed to vary between the samples. In Fig. 6, higher magnification optical images of the damage evolution mechanisms and correlation to the microstructure are presented. In the wrought $316 \mathrm{~L} \mathrm{SS}$ the damage field is comprised of disperse round voids, with void coalescence evident along the spall plane. Regions of coalesced voids linked by a network of shear localized plastic flow regions were observed. This mode of damage evolution in $316 \mathrm{~L}$ SS is similar to that observed previously on wrought $316 \mathrm{~L}$ SS [22, 23]. Higher magnification imaging of the ductile voids show that most of the voids are associated with grain boundaries suggesting that boundaries are the primary void nucleation sites similar to past observations in pure copper [24].

The damage evolution in the AM-as-built, seen in Fig. 6, displays void formation and cracks along layer solidification boundaries, the "fish-scale structure" and as well as cracks following some other layer solidification boundaries as seen in Fig. 6. The cracks and voided areas are seen to lie along boundaries nominally directly orthogonal to the shock direction. This suggests selection of regions experiencing the maximum tensile loading. Future spallation testing of samples loaded perpendicular to the AM-build direction will examine how the damage evolution is affected by the orientation of loading relative to the layer deposition direction. The microstructure within the individual solidified layer regions reveals a very fine dendritic microstructure comprised of primary and tertiary dendrites with no further evidence of evolved damage nor localized plasticity.

The damage evolution in the $\mathrm{AM}+\mathrm{Rx}$ displayed a nominally equiaxed microstructure albeit the grains exhibited a more irregular morphology. Evidence of spherical void formation at grain boundaries is seen. Some void coalescence is observed as well as jagged cracks and localized shear and cracks connecting voids was evident. In contrast to the wrought specimen, these cracks are the result of many small voids simultaneously nucleated and coalesced before significant void growth. Higher magnification of the AM-Rx incipiently spalled sample following longer chemical etching also revealed residual memory of the AM chemical segregation formed during solidification in the AM process which the recrystallization at $1060{ }^{\circ} \mathrm{C}$ for 1 hour clearly did not homogenize. Future research on $316 \mathrm{~L}$ SS produced by $\mathrm{AM}+\mathrm{Rx}$ will examine the effect of alternate heat-treatments on microstructure development.

\section{Summary}

The constitutive and spallation response of $316 \mathrm{~L}$ SS fabricated via LENS additive manufacturing is compared to that of annealed wrought 316L SS and the AM-as-built material following recrystallization, termed AM-Rx. Preliminary results indicate that the asbuilt additive 316L SS material exhibits $10 \%$ higher spall strength while displaying a $60 \%$ higher yield strength, pronounced macroscopic solidification boundary structure, and chemical segregation evident in the asbuilt microstructure compared to the equiaxed annealed wrought $316 \mathrm{~L}$ SS. The recrystallized additive $316 \mathrm{~L}$ SS material was seen to display similar quasi-static constitutive stress-strain response to the annealed wrought plate but displayed differences in terms of damage evolution methodology following spallation loading. 
Through post-build heat treatments, design of 316L SS material for specific performance objectives appears a fruitful line of research.

Los Alamos National Laboratory is operated by Los Alamos National Security, LLC, for the National Nuclear Security Administration of the U.S. Department of Energy under contract DE-AC52-06NA25396. This work was partially sponsored by the Joint DoD/DOE Munitions Technology Development Program.

\section{References}

[1] Y. Zhai, D.A. Lados, J.L. Lagoy, Journal of Metals, 66, 808 (2014)

[2] A.N. Hopkinson, P. Dickens, J. Mechanical Engineering Science, 217, 31 (2003)

[3] B.R. Berger, Additive Manufacturing: A Game Changer for the Manufacturing Industry? (Berger STrategy Consultants, Munich, Germany, 2013)

[4] T.J. Horn, O.A. Harrysson, Science Progress, 95, 255 (2012)

[5] I. Gibson, D.W. Rosen, B. Stucker, Additive Manufacturing Technologies: Rapid Prototyping to Direct Manufacturing (Springer, New York, 2010)

[6] D.L. Bourell, M.C. Leu, D.W. Rosen, Roadmap for Additive Manufacturing: Identifying the Future of Freeform Processing (University of Texas at Austin, Austin, TX, 2009)

[7] T. Foresight Project, The Future of Manufacturing: A New Era of Opportunity and Challenges for the UK (Science TGOf, London, England, 2013)

[8] T. Energetics Incorporated, Measurement Science Roadmap for Metal-Based Additive Manufacturing (Technology NIoS, Washington, DC, 2013)

[9] N.R. Council, 3D Printing in Space (The National Academy Press, Washington, DC 20001, 2014)
[10] E. Yasa, J. Deckers, J.-P. Kruth, M. Rombouts, J. Luyten, VIrtual and Physical Prototyping, 5, 89 (2010)

[11] B. Verlee, T. Dormal, J. Lecomte-BEckers, Powder Metallurgy, 55, 260 (2012)

[12] J.A. Cherry, H.M. Davies, S. Mehmood, N.P. Lavery, S.G.R. Brown, J. Sienz, International journal of Advanced Manufacturing Technology, 76, 869 (2015)

[13] A.S. Wu, D.W. Brown, M. Kumar, G.F. Gallegos, W.E. King, Metallurgical and Materials Transactions A, 45A, 6260 (2014)

[14] E. Brandl, U. Heckenberger, V. Holzinger, D. Buchbinder, Materials and Design, 34, 159 (2012)

[15] B. Baufeld, E. Brandl, O. van der Biest, Journal of Materials Process Technology, 211, 1146 (2011)

[16] J.A. Brooks, J.C. Williams, A.W. Thompson, Trends in Welding Research (ASM, 1982)

[17] G.T. Gray III, In: ASM Handbook. Vol. 8: Mechanical Testing and Evaluation, edited by Kuhn H, Medlin D, ASM International, Materials Park, Ohio(2000), p. 530

[18] O.T. Strand, D.R. Goosman, C. Martinez, T.L. Whitworth, W. W. Kuhlow, Rev. Sci. Instrum., 77, 083108 (2006)

[19] B.J. Jensen, D.B. Holtkamp, P.A. Rigg, D.H. Dolan, J. Appl. Phys., 101, 013523 (2007)

[20] P.S. Follansbee, Fundamentals of Strength (John Wiley \& Sons, Inc., Hoboken, N.J., 2104)

[21] S.A. Novikov, I.I. Divnov, A.G. Ivanov, Phys. Metals Metallog., 21(4), 122 (1966)

[22] G.T. Gray III, N.K. Bourne, B.L. Henrie, J.C.F. Millett, J. Phys. IV France, 110, 773 (2003)

[23] G.T. Gray III, N.K. Bourne, B.L. Henrie, J. Appl. Phys., 101, 093507 (2007)

[24] J.P. Escobedo, D. Dennis-Koller, E.K. Cerreta, B.M. Patterson, C.A. Bronkhorst, B.L. Hansen, D. Tonks, R.A. Lebensohn, J. Appl. Phys., 110, 033513 (2011) 